\title{
Forecasting Latin America's Country Risk Scores by Means of a Dynamic Diffusion Model
}

\author{
R. Cervelló-Royo, ${ }^{1}$ J.-C. Cortés, ${ }^{2}$ A. Sánchez-Sánchez, ${ }^{2}$ F.-J. Santonja, ${ }^{3}$ and R.-J. Villanueva ${ }^{2}$ \\ ${ }^{1}$ Department of Economics and Social Sciences, Universitat Politècnica de València, 46022 Valencia, Spain \\ ${ }^{2}$ Institute for Multidisciplinary Mathematics, Universitat Politècnica de València, 46022 Valencia, Spain \\ ${ }^{3}$ Departament of Statistics and Operations Research, Universitat de València, Burjassot, 46100 Valencia, Spain
}

Correspondence should be addressed to A. Sánchez-Sánchez; alsncsnc@posgrado.upv.es

Received 3 June 2013; Accepted 20 November 2013

Academic Editor: Benito Chen-Charpentier

Copyright (C) 2013 R. Cervelló-Royo et al. This is an open access article distributed under the Creative Commons Attribution License, which permits unrestricted use, distribution, and reproduction in any medium, provided the original work is properly cited.

Over the last years, worldwide financial market instability has shaken confidence in global economies. Global financial crisis and changes in sovereign debts ratings have affected the Latin American financial markets and their economies. However, Latin American's relative resilience to the more acute rise in risk seen in other regions like Europe during last years is offering investors new options for improving risk-return trade-offs. Therefore, forecasting the future of economic situation involves high levels of uncertainty. The Country Risk Score (CRS) represents a broadly used indicator to measure the current situation of a country regarding measures of economic, political, and financial risk in order to determine country risk ratings. In this contribution, we present a diffusion model to study the dynamics of the CRS in 18 Latin American countries which considers both the endogenous effect of each country policies and the contagion effect among them. The model predicts quite well the evolution of the CRS in the short term despite the economic and political instability. Furthermore, the model reproduces and forecasts a slight increasing trend, on average, in the CRS dynamics for almost all Latin American countries over the next months.

\section{Introduction and Motivation}

Worldwide financial market instability has shaken confidence in global economies. This loss of confidence has a strong influence on the capital flows $[1,2]$ and the investors' attitude towards some countries [3-9].

In Latin America and until the first half of 2011, the South and Central American economies expanded at a high pace. However, since late 2011, this strong growth started to slow down. This growth was particularly strong in South America (Chile, Brazil, Peru, Colombia, Uruguay, Paraguay, Argentina, Bolivia, Venezuela, Ecuador, Guyana, Suriname, Trinidad, and Tobago) due to strong economic demand, better external financing conditions, and higher commodity exportation prices, whereas in Central America (Mexico, Panama, Costa Rica, El Salvador, Guatemala, Honduras, Nicaragua, and Belize), growth has been subdued but also accelerated due to the recovery of domestic demand and a stronger agricultural expansion in Mexico. On the other hand, most of the Caribbean economies (Dominican Republic, Haiti, or Cuba) growth remained weak.

Global financial crisis and changes in sovereign debts ratings and confidence have also affected the Latin American financial markets and their economies. In fact, experiences from former currency crashes (Argentina, Mexico, etc.) are fueling avid interest in the Eurozone crisis, with the corresponding cross-country contagion. Traditional concepts of risk, solvency, liquidity, or foreign investment grade allow us to understand this issue. This is the main reason why country risk ratings have become a topic of major concern for the international financial community over the last two decades. Kaminsky and Schmmkler state: "the effects of rating and outlook changes are stronger during crisis, in nontransparent economies, and in neighboring countries" [10]. Therefore, following the series of currency crisis, policies like bailouts by both international institutions and governments have also been blamed for financial volatility and financial excesses [11, 12]. The work presented in [13] suggests that 
procyclical behavior (upgrading countries in good times and downgrading them in bad times) may have magnified the boom-bust pattern in stock markets. This effect seems to be stronger in emerging markets, where problems of asymmetric information and transparency are more severe. Furthermore, upgrades or downgrades in one country are likely to affect other similar economies.

The importance of country ratings is also underscored by the existence of several major country risk rating agencies [14]. The country risk literature argues that country risk ratings have a direct impact on the cost of borrowings as they reflect the probability of debt default by a country. An improvement in country risk ratings, or country creditworthiness, will lower a country's cost of borrowing and debt servicing obligations and vice versa $[9,15]$. For this purpose, Country Risk Scores (CRS) are built in order to measure several factors, both quantitative and qualitative. In our study we use the CRS underscored by the Euromoney Agency [16], which combines the following categories: political risk, economic performance, debt indicators, structural assessments, access to bank finance/capital markets, and credit ratings. The categories involve the following information.

(C1) Political risk

Corruption: a measure of how corruption affects country risk;

Government nonpayments/nonrepatriation: a measure of the risk Government policies and actions pose to financial transfers;

Government stability: a measure of how stable a government is;

Information access/transparency: a measure of the accessibility and reliability of information and statistics;

Institutional risk: a measure of the independence and efficiency of state institutions;

Regulatory and policy environment: a measure of the quality of the regulatory environment and how well policy is formulated/implemented.

(C2) Economic performance

Bank stability/risk: a measure of banking sector strength;

Economic Gross National Product (GNP) outlook: a measure of optimism/pessimism for the economic growth outlook;

Employment/unemployment: a measure of the risk posed to the economy by unemployment;

Monetary policy/currency stability: a measure of monetary policy effectiveness/exchange rate risk;

Government finances: a measure of a country's fiscal strength.

(C3) Debt indicators: Calculated using the following ratios from the World Bank's Global Development Finance figures: total debt stocks to GNP (A), debt service to exports (B), and current account balance to GNP (C). Developing countries which do not report complete debt data get a score of zero.

(C4) Structural assessments

Demographics: a measure of the impact of the demographic profile on economic growth and political stability;

Hard infrastructure: a measure of the adequacy of a country's physical infrastructure;

Labour market/industrial relations: a measure of the suitability of the labour environment for economic growth and political stability;

Soft infrastructure: a measure of the health of the economic, medical, and cultural/social institutions of a country.

(C5) Access to bank finance/capital markets: Participants rate each country's accessibility to international markets.

(C6) Credit ratings: Nominal values are assigned to sovereign ratings from Moody's, Standard and Poor's, and Fitch IBCA.

Thus, CRS can represent a complete indicator of the current situation of a country regarding measures of economic, political, and financial risk in order to determine country risk ratings. In the case of Euromoney Agency, the overall (ECR) Euromoney Risk Score is obtained by assigning to the six categories introduced above the following weights:

(i) Three qualitative expert opinions: political risk (30\% weighting), economic performance (30\% weighting) and structural assessment (10\% weighting),

(ii) Three quantitative values: debt indicators (10\% weighting), credit ratings (10\% weighting), and access to bank finance/capital markets (10\% weighting).

When talking about financial crises there is a lot of literature that takes into account several reasons for crises to appear in clusters $[6,8,17,18]$. Therefore, we consider that in Latin America a crisis in one Latin American country may focus investors' attention on other Latin American countries with similar trends and general structural similarities and vulnerabilities. This effect is widely known as common weakness contagion [19-22]. According to this, a cluster analysis has been performed in our study. The contagion is usually modelled using epidemiological and/or diffusion techniques. Both are in close connection and let us study the dynamics of CRS using these modelling techniques. Our objective is to predict the CRS trends over the next months, providing prediction tools for policy makers and investors. Thus, with these tools, these policy makers and investors are able to design strategies, simulate different situations, and analyse the effect of changes in order to improve the economic situation.

This paper is organized as follows. Section 2 is addressed to introduce the available data, to perform a cluster analysis, 


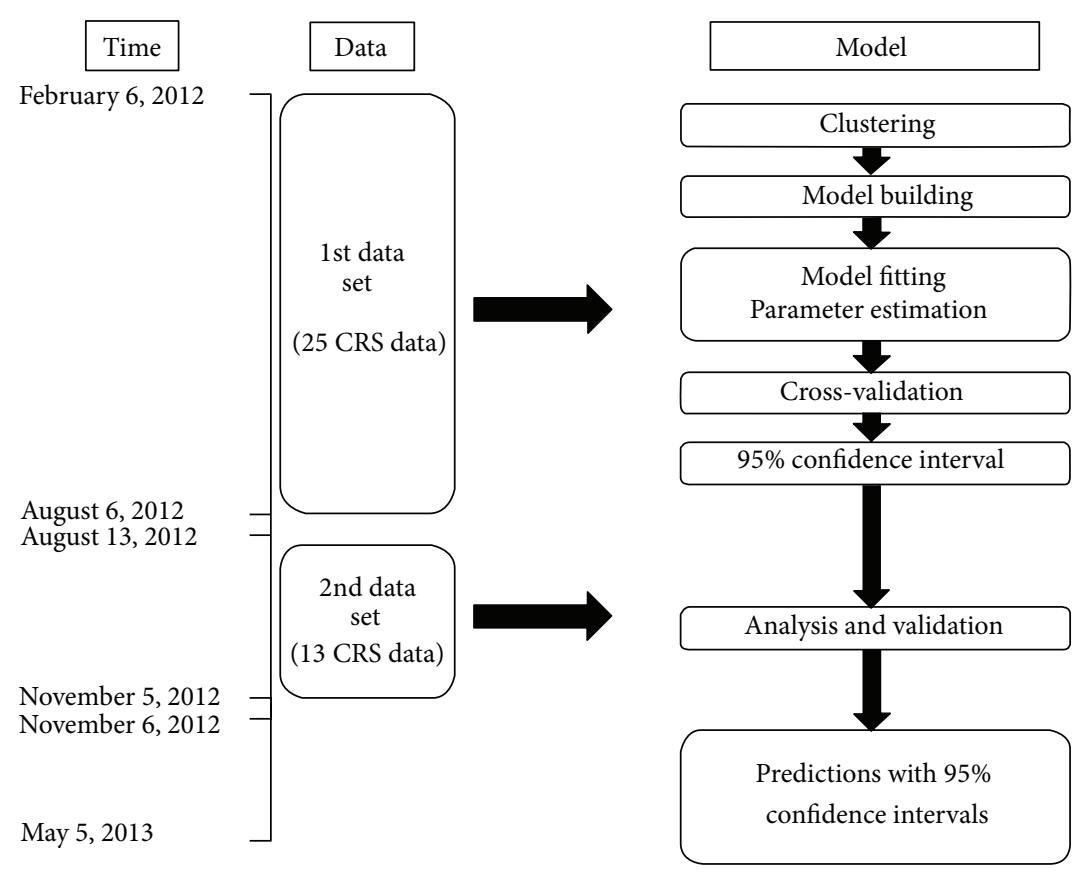

FIGURE 1: Scheme summarizing the techniques applied through this paper.

and to construct and justify the mathematical model used to describe the dynamics of the CRS of 18 Latin American countries. First part of Section 3 is devoted to model parameter estimation. Since uncertainty and variability are the rules when dealing with modelling real problems, in the second subsection, we provided predictions by means of confidence intervals using a cross-validation technique. In the third part the model is validated and the results are discussed in Section 3.3. Figure 1 summarizes the aforementioned processes developed in this approach. Conclusions are drawn in Section 4.

\section{Modelling}

This section is addressed to construct and justify the mathematical model used to describe the dynamics of the CRS of the 18 most important Latin American countries (listed in Table 1). To perform the study we have considered a total of 25 available values of CRSs for every country corresponding to different dates starting from February 6, 2012, to August 6, 2012 [16]. Table 2 collects the CRS numerical values corresponding to the starting date and all CRS values are graphically represented as black points in Figures 4 and 5.

2.1. Clustering. As we said previously, in finance and especially in country risk assessment, it is useful to group the different countries sharing similar economic characteristics. The clustering technique allows us to gather the different countries into homogeneous groups. Thus, before constructing our dynamic diffusion model, we have performed a clustering. As we will see later, an additional advantage of the clustering is the reduction of the number of model parameters to be estimated. In order to deal with this task, we have
TABLE 1: Clustering obtained by non-hierarchical clustering technique.

\begin{tabular}{lccccc}
\hline$i$ & Country name & Cluster & $i$ & Country name & Cluster \\
\hline & & & 8 & Honduras & 3 \\
& & & 9 & Ecuador & 3 \\
& Chile & 1 & 10 & Nicaragua & 3 \\
& & & 11 & Dominican Republic & 3 \\
& & & 12 & Trinidad and Tobago & 3 \\
\hline 2 & Brazil & 2 & 13 & Costa Rica & 4 \\
3 & Mexico & 2 & 14 & Paraguay & 4 \\
4 & Peru & 2 & 15 & El Salvador & 4 \\
5 & Colombia & 2 & 16 & Argentina & 4 \\
6 & Uruguay & 2 & 17 & Bolivia & 4 \\
7 & Panama & 2 & 18 & Venezuela & 4 \\
\hline
\end{tabular}

used the non-hierarchical clustering (also termed $k$-means clustering) [23, 24]. This method separates $i$ observations into $k$ clusters in which each observation belongs to the cluster with the nearest mean. Applying this technique, Latin American countries $(i=1,2, \ldots, 18)$ have been grouped into four clusters considering the available data corresponding to the six categories C1-C6 introduced in the previous section. The results are reported in Table 1.

The first cluster gathers Chile, the safest and most prosperous South American economy. It should be also remarked that it leads Latin American nations to human development, competitiveness, income per capita, globalization, economic freedom, and low perception of corruption [25]. The second cluster gathers both South American (Brazil, Peru, Colombia, and Uruguay) and Central American countries (Mexico and Panama) economies which have done better in the last 10 
TABLE 2: Initial CRS data corresponding to February 6, 2012 (Euromoney, 2012 [16]).

\begin{tabular}{lccc}
\hline Country name & Initial CRS & Country name & Initial CRS \\
\hline \multirow{3}{*}{ Chile } & & Honduras & 37.95 \\
& 75.07 & Ecuador & 34.25 \\
& & Nicaragua & 31.43 \\
& & Dominican Rep. & 35.40 \\
Brazil & 62.76 & Trinidad Tobago & 51.59 \\
Mexico & 58.93 & Costa Rica & 52.27 \\
Peru & 55.76 & Paraguay & 41.40 \\
Colombia & 59.61 & Al Salvador & 42.73 \\
Uruguay & 50.61 & Bolivia & 59.61 \\
Panama & 57.78 & Venezuela & 35.38 \\
\hline
\end{tabular}

years, with Brazil and Mexico being the leaders of the group. The third cluster includes Central American (Honduras and Nicaragua), South American (Ecuador), and Caribbean (Dominican Republic and Trinidad and Tobago) countries which have suffered a weaker growth in the last 10 years. The fourth cluster includes the considered less safe attractive investing and also most unstable South American (Argentina, Bolivia, Venezuela, and Paraguay) and Central American (Costa Rica and El Salvador) countries due to its politicalsecurity and/or economic situation.

In the following, for our dynamic diffusion model, we are going to assume that the obtained clustering does not change over the time. This hypothesis is reasonable because, as we said previously, we are going to predict CRS evolution in a short time and there will be very few countries that may move out from one cluster to another in the studied period. Furthermore, the obtained clusters represent quite accurately the current economic Latin American groups.

2.2. Mathematical Model. Once the clusters have been established, we propose a diffusion dynamic model to study the evolution of the CRS of each Latin American country. Diffusion dynamic models have been demonstrated to be powerful tools to study a wide range of applied problems in different areas including economics and its related fields [2628]. Although complex models have been proposed based on this approach, they all follow the next pattern:

$$
x^{\prime}(t)=\beta(t) x(t),
$$

where $x(t)$ represents the magnitude under modelling (in our case, the CRS to each Latin American country at time $t$ ), $x^{\prime}(t)$ denotes the derivative with respect to the time $t$ (it may also be denoted by $d x(t) / d t)$, and $\beta(t)$ is the so-called time-dependent diffusion coefficient, which may involve the unknown $x(t)$. This coefficient is basically what differentiates one specific model from another. Our model considers $\beta(t)$ as a linear function of the unknowns which can be decomposed into two factors: the first one represents, through CRS, the autonomous economic behavior of each country and the second one the contagion effect for loss or gain of confidence both between and within clusters for each country. As we will see, in our case the resulting model will be nonlinear.

For the sake of clarity in the model setting, we will identify each one of the 18 Latin American countries with the index $i=1,2, \ldots, 18$ according to the same order obtained after clustering (see Table 1). Now, it is convenient to denote the indexes $j_{k}$ and the values $J_{k}, 1 \leq k \leq 4$, as follows:

$$
\begin{gathered}
1 \leq j_{1} \leq J_{1}=1, \quad 1 \leq j_{2} \leq J_{2}=6, \\
1 \leq j_{3} \leq J_{3}=5, \quad 1 \leq j_{4} \leq J_{4}=6, \\
\sum_{k=1}^{4} J_{k}=18,
\end{gathered}
$$

where $J_{k}$ is the number of countries in cluster $k$. We assume that CRS variation rate of a country, modelled by its derivative $C_{i}^{\prime}(t), 1 \leq i \leq 18$, is a mixture of an autonomous term, related to its endogenous economic politics, and several diffusion terms, related to the exogenous economic influences of other Latin American countries belonging to the same or different cluster. In the following, we describe in detail these terms.

Autonomous Behavior. Each Latin American country develops endogenous politics that may result in an increase or decrease in its own CRS. We model this autonomous behavior by $\alpha_{i} C_{i}(t), 1 \leq i \leq 18$. The coefficient $\alpha_{i}$ can take positive or negative values which are identified, respectively, with suitable and unsuitable domestic politics, with respect to its CRS.

Transmission Behavior. In an economically globalized world, the economic situation of a specific country could eventually influence other countries. This statement is even more realistic for a set of countries sharing similar economic characteristics, like Latin American countries. Initially, this might motivate to establish a dynamic diffusion model by considering a full contagion between each pair of countries. However this approach entails the introduction of a large number of parameters, what would make the model parameter estimation computationally unfeasible. In order to reduce the number of model parameters, we take advantage of previous clustering classification to consider as a balanced CRS' indicator of each cluster the following average value:

$$
\bar{C}_{k}(t)=\frac{1}{J_{k}} \sum_{j_{k}=1}^{J_{k}} C_{j_{k}}(t), \quad 1 \leq k \leq 4
$$

Based on the CRS, we propose to model the influence of the economic policies of the countries belonging to the cluster $k$, $1 \leq k \leq 4$, on the $i$ th Latin American country, $1 \leq i \leq 18$, according to the following term ( $t$ measured in years):

$$
\beta_{k(i), k} C_{i}(t)\left(\bar{C}_{k}(t)-C_{i}(t)\right), \quad \beta_{k(i), k}>0,1 \leq k \leq 4,
$$


where the first subindex $k(i)$ of coefficient $\beta_{k(i), k}$ denotes the cluster to which the $i$ th country belongs:

$$
k(i)= \begin{cases}1 & \text { if } 1 \leq i \leq 1=J_{1}, \\ 2 & \text { if } 2 \leq i \leq 7=J_{1}+J_{2} \\ 3 & \text { if } 8 \leq i \leq 12=J_{1}+J_{2}+J_{3}, \\ 4 & \text { if } 13 \leq i \leq 18=J_{1}+J_{2}+J_{3}+J_{4} .\end{cases}
$$

In order to include all the possible influences of countries belonging to every cluster on the $i$ th country $(1 \leq i \leq 18)$, we consider the sum of all the transmission terms (4) as follows.

$$
\begin{array}{r}
C_{i}(t) \sum_{1 \leq k, k(i) \leq 4} \beta_{k(i), k}\left(\bar{C}_{k}(t)-C_{i}(t)\right), \\
\beta_{k(i), k}>0,1 \leq k \leq 4,
\end{array}
$$

where $k(i)$ is given by (5). The two factors that determine each summand in (6) can be interpreted as follows.

(i) The term $\bar{C}_{k}(t)-C_{i}(t)$ measures the CRS difference (positive or negative) between the $i$ th country at time $t$, denoted by $C_{i}(t)$, and the CRS average of countries belonging to cluster $k$ at the same time $t$, denoted by $\bar{C}_{k}(t)$. So, we assume that this factor contributes positively (negatively) to the transmission term (4) when the $i$ th country has a CRS lower (higher) than the CRS average of countries in cluster $k$. Thus, we suppose that countries with lower (higher) CRS than those belonging to a cluster with higher (lower) average CRS tend to increase (decrease) their CRS influenced by the countries belonging to cluster $k$.

(ii) The factors responsible for the contagion effect are embedded in the $\beta_{k(i), k}$ coefficients, and they modulate the weight of the differences $\bar{C}_{k}(t)-C_{i}(t)$ in the transmission terms. Notice that, once the subindex $k$ is fixed, we are assuming that this coefficient $\beta_{k(i), k}$ is the same for every country belonging to the same cluster $k(i)$. This reduces the total number of $\beta_{k(i), k}$ up to 16 .

Taking into account the previous exposition that includes both autonomous and transmission behavior, we propose the following diffusion dynamic model, based on a coupled system of 18 nonlinear differential equations, one per country, to study the dynamic evolution of the CRS's Latin American countries:

$$
\begin{aligned}
C_{i}^{\prime}(t)= & \alpha_{i} C_{i}(t)+\sum_{1 \leq k, k(i) \leq 4} \beta_{k(i), k} C_{i}(t) \\
& \times\left(\bar{C}_{k}(t)-C_{i}(t)\right), \quad 1 \leq i \leq 18,
\end{aligned}
$$

where $k(i)$ is defined by (5) and $\alpha_{i} \in \mathbb{R}$ and $\beta_{k(i), k}>0$ are the $18+16=34$ model parameters.

\section{Probabilistic Predictions over the Next Few Months}

This section is divided into three subsections. The first one, is devoted to model parameters estimation. Since uncertainty
TABLE 3: Estimation of the autonomous model parameters, $\alpha_{i}$, separated by clusters.

\begin{tabular}{lccc}
\hline Country name & $\alpha_{i}$ & Country name & $\alpha_{i}$ \\
\hline & & Honduras & -0.0440 \\
& & Ecuador & -0.5731 \\
Chile & 1.6844 & Nicaragua & -0.7551 \\
& & Dominican Rep. & -0.4340 \\
& & Trinidad Tobago & 1.3411 \\
\hline Brazil & 1.8554 & Costa Rica & 1.0763 \\
Mexico & 1.2784 & Paraguay & -0.0203 \\
Peru & 1.1126 & El Salvador & 0.4658 \\
Colombia & 1.5382 & Argentina & -0.4093 \\
Uruguay & 0.0696 & Bolivia & -0.5837 \\
Panama & 1.2563 & Venezuela & -0.4590 \\
\hline
\end{tabular}

TABLE 4: Estimated values of the contagion model parameters. The value of model parameter $\beta_{k(i), k}$ measures the contagion effect transmitted by the countries belonging to cluster $k(1 \leq k \leq 4)$ on country $i(1 \leq i \leq 18)$ belonging to cluster $k(i)$ according to assignment (5). Figures indicate that countries in clusters $k=3,4$ have a remarkable influence on the others, being lower on Chile (columns 3 and 4). In addition, it can be observed that Chile (cluster 1) has a strong influence on countries which belong to cluster 2 (element $(2,1)$, whose value is 0.01122$)$.

\begin{tabular}{lcccc}
\hline$\beta_{k(i), k}$ & $k=1$ & $k=2$ & $k=3$ & $k=4$ \\
\hline$k(i)=1,1 \leq i \leq 1$ & 0 & 0.01122 & 0.02525 & 0.01736 \\
$k(i)=2,2 \leq i \leq 7$ & 0.05222 & 0.00007 & 0.04198 & 0.07828 \\
$k(i)=3,8 \leq i \leq 12$ & 0.00047 & 0.00180 & 0.03809 & 0.04129 \\
$k(i)=4,13 \leq i \leq 18$ & 0.00004 & 0.00283 & 0.04903 & 0.04771 \\
\hline
\end{tabular}

and variability are the rules when dealing with modelling real problems, in the second subsection, we provide predictions by means of confidence intervals obtained using a crossvalidation technique. In the third one, we validate and discuss the obtained results.

3.1. Parameter Estimation. As we have previously pointed out, this subsection is firstly addressed to estimate the parameters of model (7). This task has been performed by fitting the model in the mean square sense to the available data using optimization techniques. Computations have been carried out with Mathematica 8.0 [29].

The system of differential equations (7) is numerically solved by taking as initial conditions the CRS data of February 6, 2012 (corresponding to $t=0$ ), that is, according to Table 2 . Tables 3 and 4 report the estimation of the autonomous $\left(\alpha_{i}\right)$ and contagion $\left(\beta_{k(i), k}\right)$ model parameters.

For the sake of clarity, in Figure 2 we have depicted the estimation of the autonomous model parameters in four plots according to previous clustering. Notice that countries in cluster 2 have similar values for autonomous decision except for Uruguay (identified by number 5 in cluster 2) whose gross public sector debt contracted in the second quarter of 2010, after five consecutive periods of sustained increase and reached the equivalent to $59.5 \%$ of the GDP [30]. Analogously, in cluster 3 except for Trinidad and Tobago (identified by number 5), which is considered one of the wealthiest 
Cluster 1

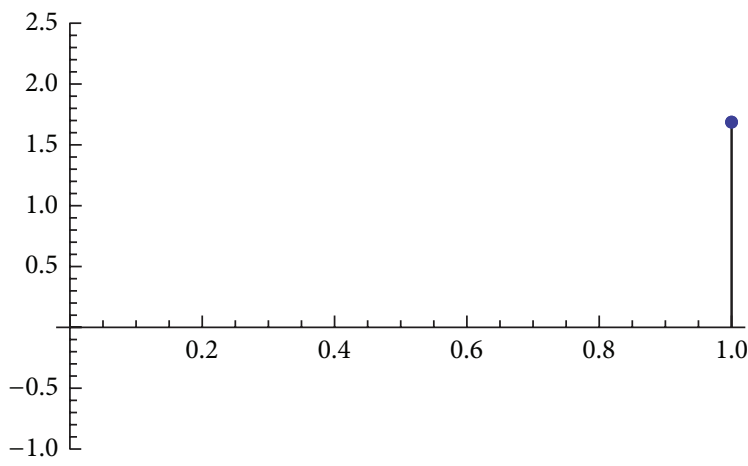

(a)

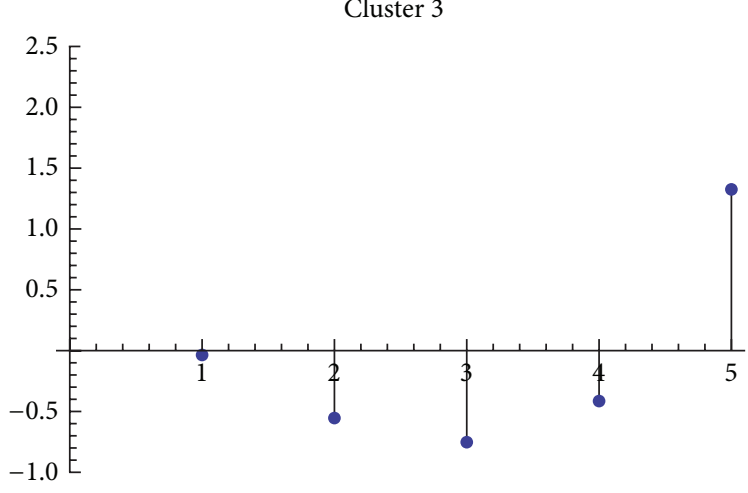

(c)
Cluster 2

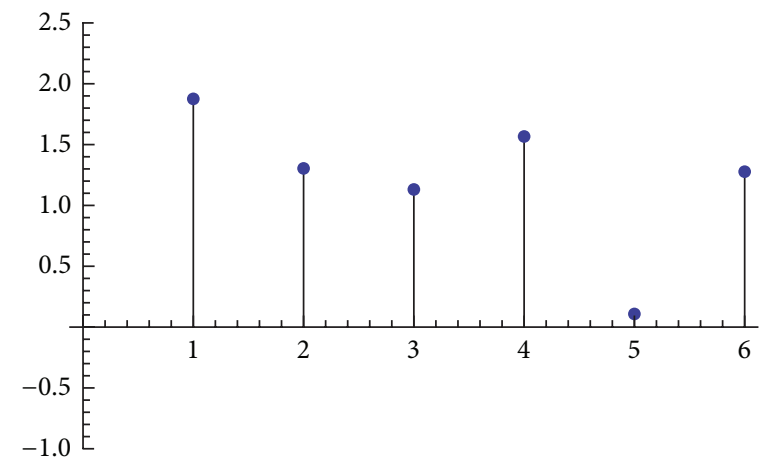

(b)

Cluster 4

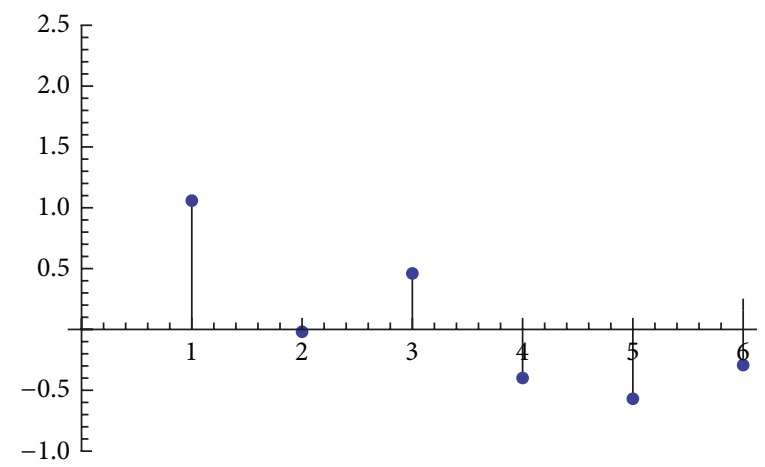

(d)

FIGURE 2: Representation of the estimation of the autonomous model parameters, $\alpha_{i}$, per cluster. Notice that countries in cluster 2 have similar values for autonomous decision except for Uruguay (identified by number 5 in cluster 2) whose gross public sector debt contracted in the second quarter of 2010, after five consecutive periods of sustained increase, and reached the equivalent to 59.5\% of the GDP [30]. Analogously, in cluster 3 except for Trinidad and Tobago (identified by number 5), which is considered one of the wealthiest and most developed nations in the Caribbean [31]. The countries are in the same order as they appear in Table 3.

and most developed nations in the Caribbean [31]. Also, looking at Table 4, observe that the estimated transmission parameters suggest that except for Chile (cluster 1) countries in clusters $k=3,4$ have a remarkable influence on the rest of the countries. In addition, it can be observed that Chile (cluster 1) has a strong influence on countries which belong to cluster 2 (see Figure 3).

In Figure 4, we can see graphically the model fitting for every Latin American country. The solid lines plotted represent the model approximation for all the countries of each cluster, namely, cluster 1: Chile; cluster 2: Brazil, Mexico, Peru, Colombia, Uruguay, and Panama; cluster 3: Honduras, Ecuador, Nicaragua, Dominican Rep., and Trinidad Tobago; cluster 4: Costa Rica, Paraguay, El Salvador, Argentina, Bolivia, and Venezuela. The black points represent the available data of CRS which have been used to fit the model. Taking into account the scale in vertical axis, the model fits accurately the available data.

3.2. Introducing Uncertainty into the Model: Predictions over the Next Few Months Using Confidence Intervals. Randomness can be attributed not only to sampling errors in the data but also to the inherent complexity of the phenomenon under study. This statement particularly holds in dealing with economic problems such as forecasting CRS, since there are large jumps in CRS points in several countries with a difference of a week (until 4.2 CRS points in Trinidad and Tobago). Therefore, it is more realistic to construct predictions by confidence intervals. To calculate these intervals, let us use an adaptation of the statistical technique usually referred to as Cross-Validation or rotation estimation [32, 33]. CrossValidation is a versatile statistical method of evaluating and comparing learning algorithms by dividing data into two segments: one used to learn or train the model and the other used to validate the model. Apart from its basic formulation, several variations of Cross-Validation have been proposed to get other statistical goals including the estimation of model parameters $[34,35]$.

The version of the Cross-Validation process we propose is the following:

(i) we have 18 CRS data sets, one for each country, for 25 different time instants between February 6, 2012, and August 6, 2012 (1st data set, the black points in Figures 4 and 5) and for 13 different time instants between 


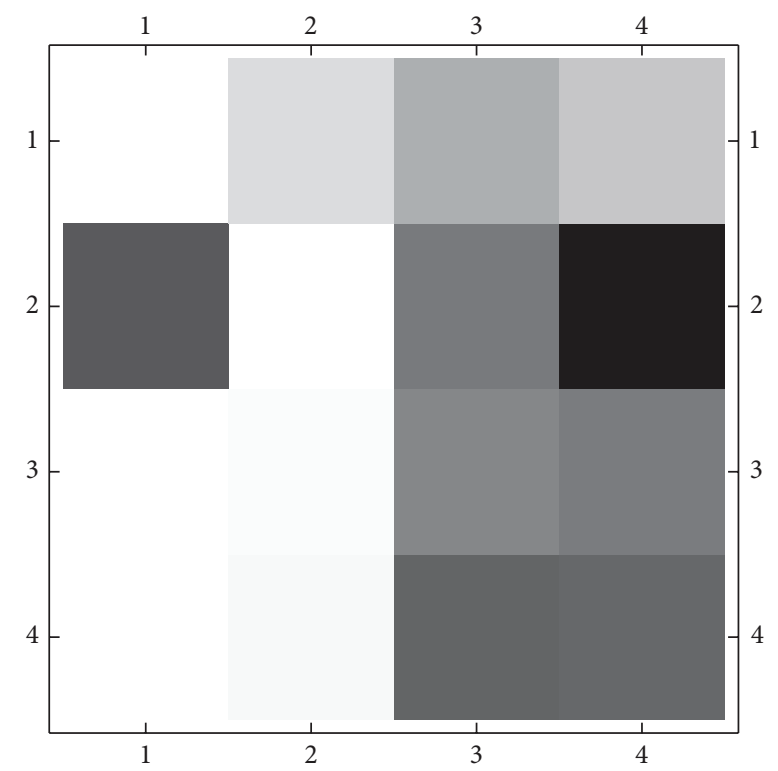

FIGURE 3: In this figure we use a grayscale to represent the level of contagion from cluster in column $j$ to cluster in row $i(1 \leq i, j \leq 4)$ (the darker the more contagion).

August 13, 2012 and November 5, 2012, for further model validation (2nd data set, the green points in Figure 5);

(ii) we take the CRS data corresponding to $h$ time instants among the 25 available in the 1st data set. There are a lot of combinations for taking $h$ time instants among 25 . However, in case that the number of combinations is greater than 5,000, we take randomly 5,000. Let $n_{h}$ be the number of selected combinations with $h$ data;

(iii) we fit the model with each one of the $n_{h}$ selected combinations of $h$ data taking as the model initial condition the earliest ordered data, obtaining a set of $n_{h}$ estimations of the model parameters;

(iv) we substitute each one of the obtained $n_{h}$ estimated parameters into the model and solve it numerically;

(v) we compute the model outputs for the $n_{h}$ model solutions in the known 25 time instants of the 1st data set and the 13 time instants of the 2 nd data set;

(vi) for each time instant, we have $n_{h}$ model output values and we can obtain the $95 \%$ confidence interval by computing percentiles 2.5 and 97.5 of the $n_{h}$ data.

Among all the values of $h$ used, we determine as the best one which makes the maximum number of CRS data in 1st and 2 nd set lie inside the $95 \%$ confidence interval. Then, we will be able to provide reliable probabilistic predictions extending the 95\% confidence intervals 6 months after November 5, 2012 (end of the 2nd data test). After testing all the combinations, the best obtained value is $h=3$, where $98.44 \%$ of the 1st data set (443 out of 450 ) and $73.08 \%$ of the 2nd data set (171 out of 234) lie inside their corresponding $95 \%$ confidence intervals.
Considering the relevance of each cluster for our study, we have selected at least one representative country taking into account the different performance of CRS in the countries belonging to each cluster. Thus, we selected Chile as representative of cluster 1; Mexico, Brazil, and Uruguay of cluster 2; Ecuador in case of cluster 3; and Paraguay, Argentina, Bolivia, and Venezuela as representatives of cluster 4 .

In Figure 5 we can see graphically the probabilistic prediction of the CRS of the aforementioned countries extending the $95 \%$ confidence intervals 6 months after November 5, 2012. Additionally, the 1st data set (black points) and the 2nd data set for validation (green points) are presented. To obtain Figure 5 we calculate $95 \%$ confidence intervals (red lines) and their mean (dashed line) from April 2, 2012, to May 5, 2013, with time jumps of 0.01 .

3.3. Validation and Discussion. According to the obtained results, we should remark the difficult task of forecasting the complex economic dynamics of 18 Latin American countries considering the current international scenario, added to the uncertainty in the global economy. The CRS data behavior reflects these circumstances, since for some CRS data, we can observe sudden large jumps in a short time.

Now, we proceed to predict and validate the model. With this aim, we gather new actual and current CRS data, in particular, from August 13, 2012, to November 5, 2012 (the 2nd data set), data that we did not use initially to fit the model because they were not available at that time. These new data allow us to compare and validate the obtained predictions from our model with the new real data.

Looking at Figure 5, in general, there is a certain stability or a slight increasing trend in the CRS for all the countries over the next few months with uncertainties given by $95 \%$ confidence intervals. More precisely, considering the average prediction (dashed lines) there is less uncertainty in the lower range of the confidence intervals than in the upper ones.

The $95 \%$ confidence intervals provide a quite accurate forecasting for almost all considered countries, being not wider than 5 CRS points for all the countries for early May 2013. In fact, the confidence intervals contain almost all the black points (98.44\%) and a high percentage of the green points (73.08\%). Also, most of the points outside the $95 \%$ confidence intervals are relatively close to them. On average, the total percentage of points that lie inside the confidence intervals is up to $89.77 \%$, a high rate taking into account the uncertainty of economic and political situation of some countries.

Argentina and Venezuela are the countries where the forecasting has been least valid. In particular, in the case of Argentina, it can be noted that from late January 2012 (42.29 CRS points) to early November 2012 (34.46 CRS points), there is a drop of 8 CRS points due to the tensions derived from the government interference and expropriation. However, the $95 \%$ confidence intervals forecast the period August 13th until September 24 when a drop of a CRS points is experienced because of its rising expropriation risk and its nonpayment debt risk. A right prediction of 6 weeks in Argentina is not a minor issue due to its instability. However, we only predict correctly 3 weeks for Venezuela. 


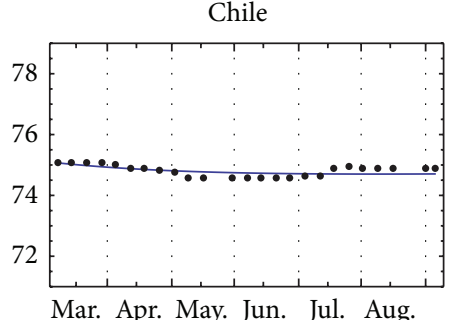

Peru
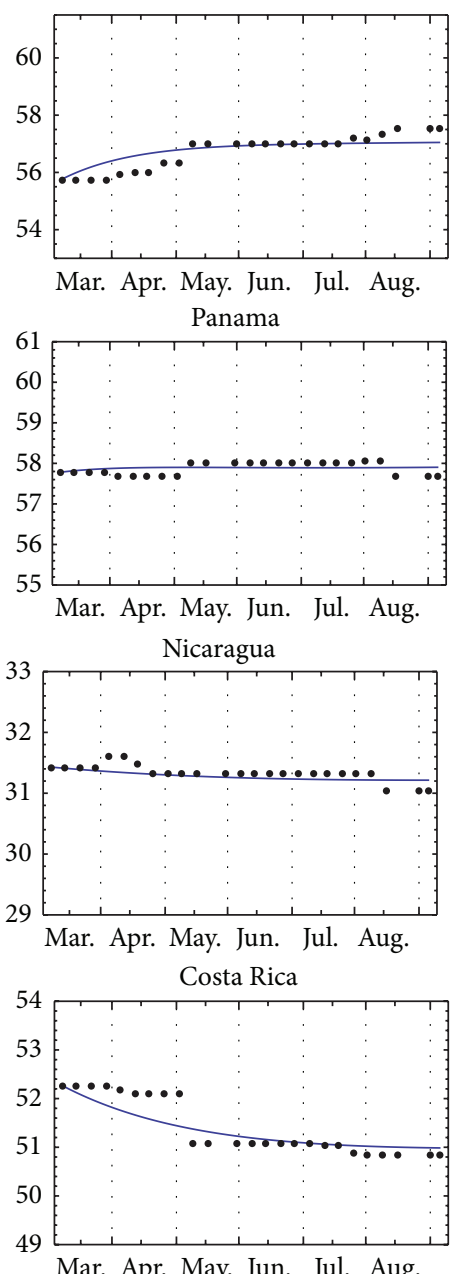

Mar. Apr. May. Jun. Jul. Aug.

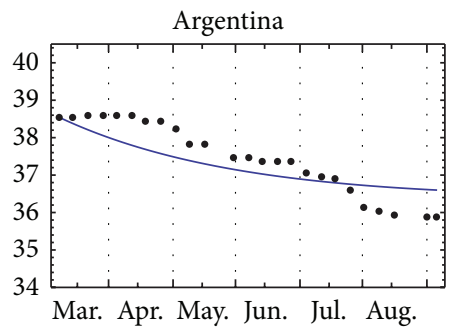

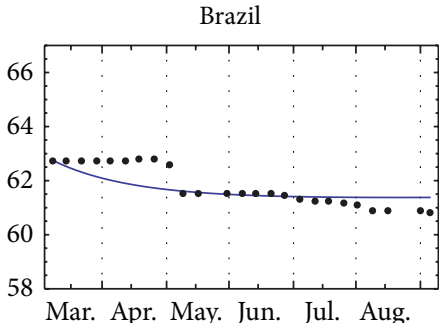

Colombia
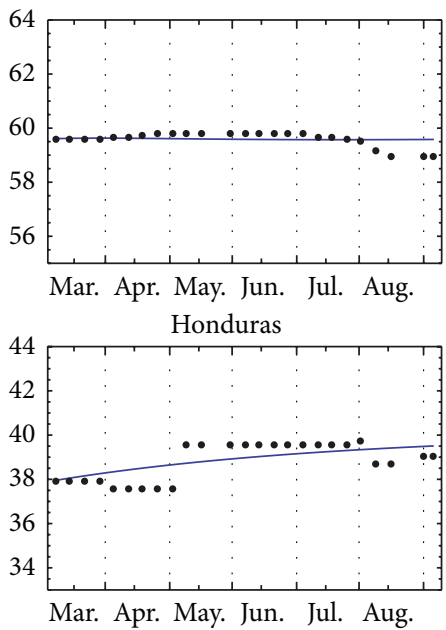

Dominican Republic

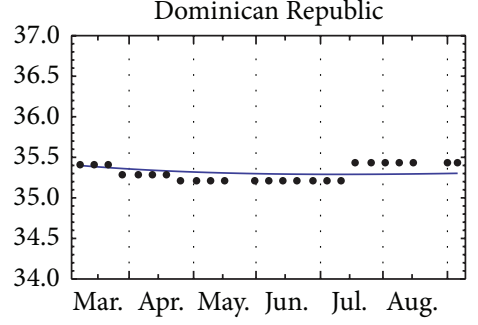

Paraguay

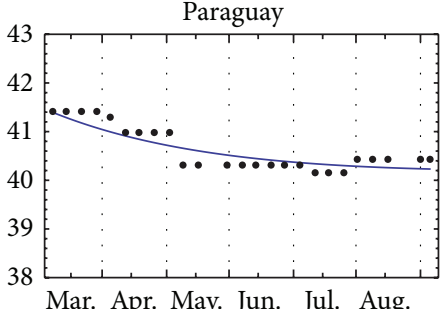

Bolivia

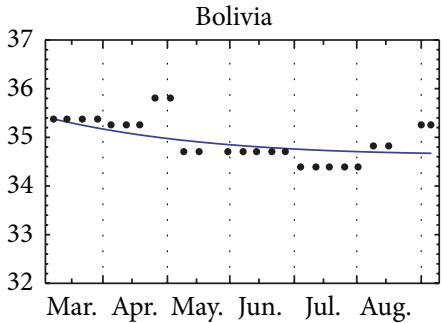

Mexico

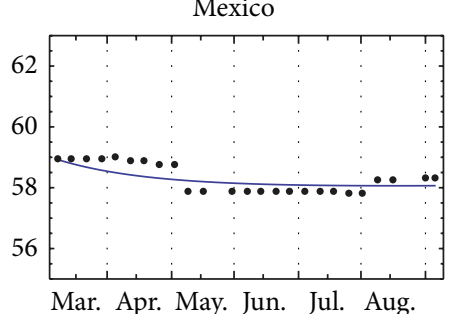

Uruguay
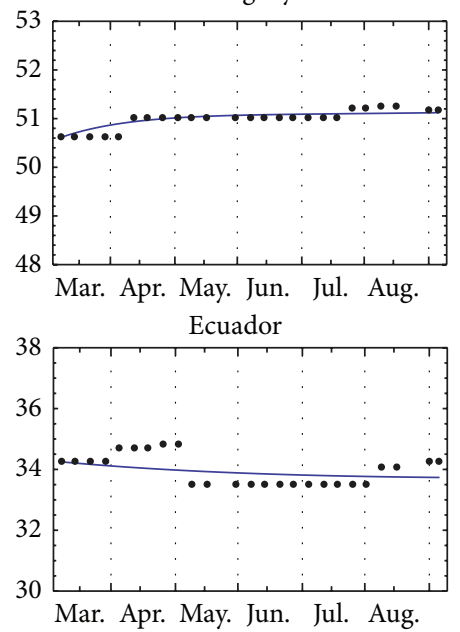

Trinidad and Tobago

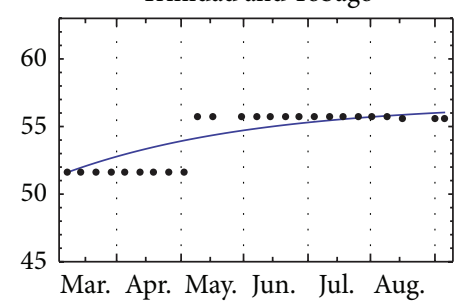

El Salvador

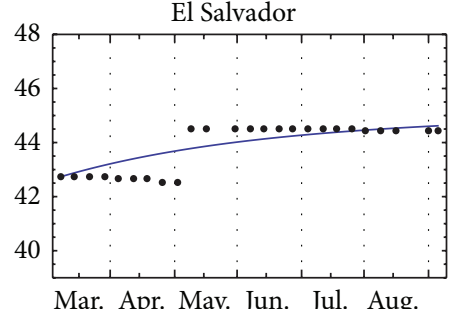

Venezuela

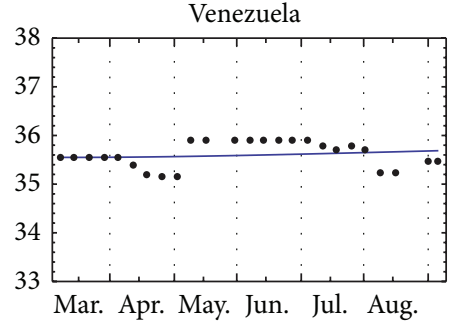

FIGURE 4: CRS fitting for the 18 selected Latin American countries. The solid line is the model solution for the parameters of Tables 3 and 4 that best fit the model. The points are the known CRS data from February 6, 2012, to August 6, 2012. Notice the different vertical scales in the plots for each country. 


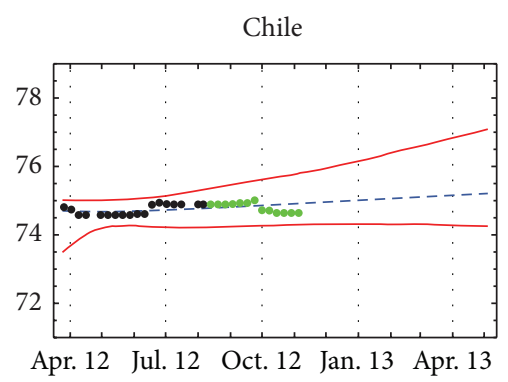

(a)

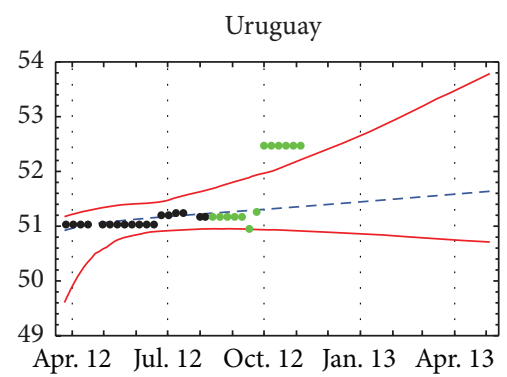

(d)

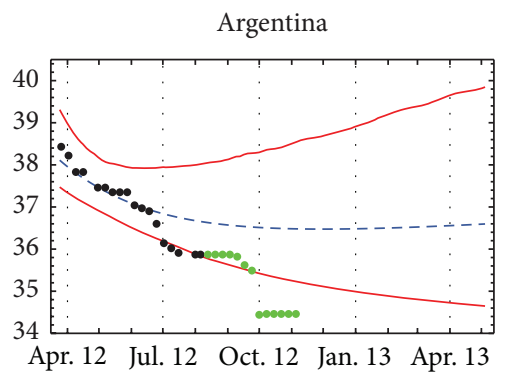

(g)

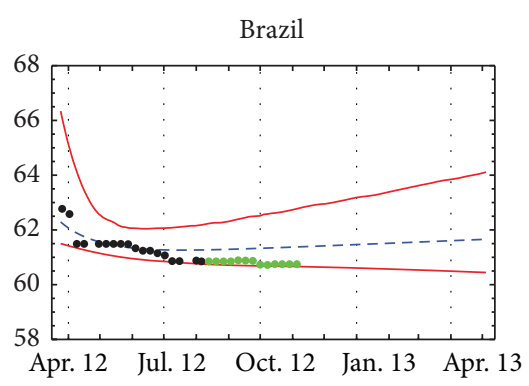

(b)

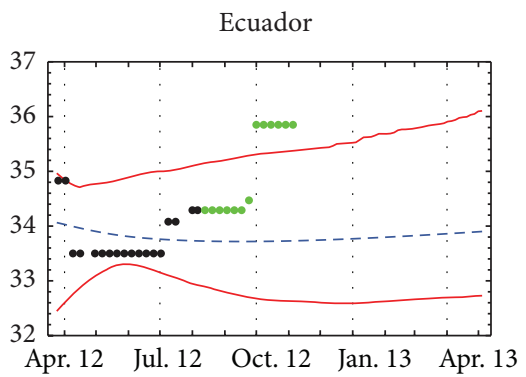

(e)

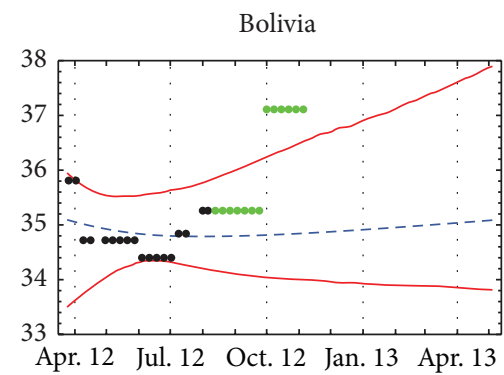

(h)

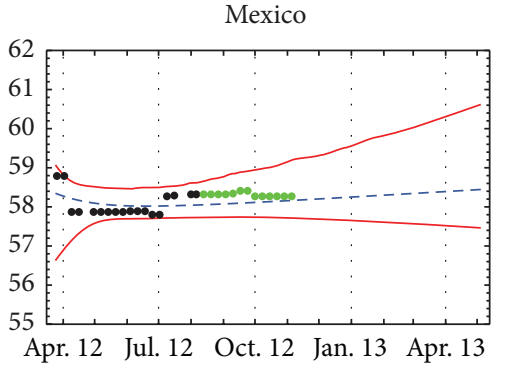

(c)

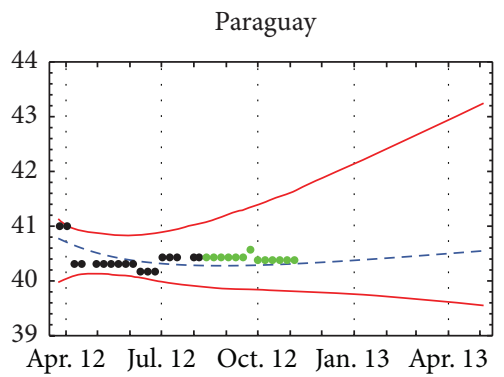

(f)

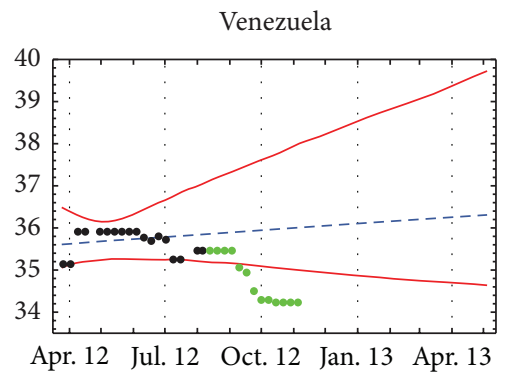

(i)

Figure 5: Probabilistic Country Risk Score forecasting for selected Latin American countries belonging to each cluster (cluster 1: Chile; cluster 2: Brazil, Mexico, and Uruguay; cluster 3: Ecuador; cluster 4: Paraguay, Argentina, Bolivia, and Venezuela). The dashed line is the mean of the $95 \%$ confidence interval and the red lines correspond to 95\% confidence intervals between April 2, 2012, and May 5, 2013. The drawn black points are the known CRS of the 1st data set. The green points are the actual and current available data (from August 13, 2012, to November 5,2012 ) used in order to validate the model, the 2 nd data set. Notice that every plot has its own numerical range in the vertical axis.

In countries like Uruguay, Ecuador, and Bolivia, we also have a right prediction of 6 weeks, when an increasing jump of 1.2-1.9 CRS points arose the last week of September. However, we should take into account that, if the jumps had happened 1-2 months later, the corresponding 95\% confidence intervals would have captured these jumps. In some way, the jumps are predicted by the model with a delay. This does not happen with Argentina or Venezuela. On the other hand, quite accurate predictions are obtained for countries with an economic and political stability such as Chile, Brazil, Mexico, and Paraguay since the $95 \%$ confidence intervals provided by the Cross-Validation contain all the points considered for validation. In fact, it is possible that, for these stable countries, our forecasting keeps valid longer than the 3 months of available data (2nd data set).

Thus, our model allows for predicting a longer period of time for most of the countries. However, the economic and political instability of some countries involves jumps of some CRS points which might not permit the predictions to be as accurate as in the more stable countries.

\section{Conclusions}

Worldwide financial crisis and changes in sovereign debts ratings have also affected the Latin American financial markets and their economies. However, Latin America's relative resilience to more acute rise in risk seen in other regions like Europe during last years is offering investors new options to improve risk-return trade-offs. Country Risk Score (CRS) represents a measure of the level of confidence on each country and a measure of its economic health. Latin America, a regional grouping of several countries, has also invariably succumbed to increased risk this year, according to Euromoney's Country Risk Survey, in line with the global trend. 
In this work, we present a dynamic diffusion model to study the evolution of the Country Risk Score (CRS), for a total of 18 Latin American countries, which considers both the endogenous effect of each country politics and the contagion effect among them. Using data of CRS, we fit the model with the data estimating unknown autonomous behavior and transmission parameters. Then, we use an adapted Cross-Validation technique in order to provide probabilistic predictions over the next months (August 2012 until May 2013) taking into account that most of CRS data should be inside the confidence intervals corresponding to their time instants.

The obtained results depict quite well the evolution of the CRS for most of the countries, despite the jumps and uncertainty in the CRS data within some periods. Chile is still holding its own as the darling of the region, and Brazil remains the second safest. However, whereas seems to be more confidence in Uruguay and Ecuador, faith in Venezuela and Argentina has diminished alarmingly. The increased perception of risk stems from a range of domestic and external factors, from political and economic policy failings in Argentina to worries about the impact of dissipating global growth prospects for the region's exports.

As we have remarked, it should be pointed out that mathematical modelling with probabilistic predictions may be a powerful tool where policy makers and investors are able to design strategies, modify the model parameters in order to simulate them, and analyse the effect of changes. Looking back at the last year, the Latin American score decline is relatively mild in comparison with the falls seen in countries which belong to the Eurozone and Central and Eastern Europe. As we can check in our results even over next months horizon, Latin America might held up fairly well, despite an average score loss driven by drops for Argentina and Venezuela.

\section{Acknowledgments}

This work has been partially supported by the Spanish M.C.Y.T. Grants MTM2009-08587 as well as the Universitat Politècnica de València Grant PAID06-11 (ref. 2070).

\section{References}

[1] E. Fernández-Arias and P. J. Montiel, "The surge in capital inflows to developing countries: an analytical overview," World Bank Economic Review, vol. 10, no. 1, pp. 51-77, 1996.

[2] M. P. Taylor and L. Sarno, "Capital flows to developing countries: long- and short-term determinants," World Bank Economic Review, vol. 11, no. 3, pp. 451-470, 1997.

[3] R. Dornbusch, Y. C. Park, and S. Claessens, "Contagion: understanding how it spreads," World Bank Research Observer, vol. 15, no. 2, pp. 177-197, 2000.

[4] S. Edwards and R. Susmel, "Interest rate volatility and contagion in emerging markets: evidence from the 1990," NBER Working Paper 7813, 2000.

[5] S. Edwards and R. Susmel, "Volatility dependence and contagion in emerging equity markets," NBER Working Paper 8506, 2001.
[6] K. Forbes and R. Rigobon, "Measuring contagion: conceptual and empirical issues," in International Financial Contagion, S. Claessens and K. Forbes, Eds., Kluwer Academic Publishers, Boston, Mass, USA, 2001.

[7] L. E. Kodres and M. Pritsker, "A rational expectations model of financial contagion," Journal of Finance, vol. 57, no. 2, pp. 769799, 2002.

[8] P. R. Masson, "Contagion: monsoonal effects, spillovers and jumps between multiple equilibria," in The Asian Crises: Causes, Contagion and Consequences, P. Agenor, M. Miller, and D. Vines, Eds., Cambridge University Press, Cambridge, UK, 1999.

[9] S. Hoti, "Comparative analysis of risk ratings for the East European region," Mathematics and Computers in Simulation, vol. 68, no. 5-6, pp. 449-462, 2005.

[10] G. Kaminsky and S. L. Schmukler, "Emerging market instability: do sovereign ratings affect country risk and stock returns?" World Bank Economic Review, vol. 16, no. 2, pp. 171-195, 2002.

[11] M. Dooley, "A model of crises in emerging markets," NBER Working Paper 6300, National Bureau of Economic Research, Cambridge, UK, 1998.

[12] R. I. McKinnon and H. Pill, "Credible economic liberalizations and overborrowing," American Economic Review, vol. 87, no. 2, pp. 189-193, 1997.

[13] G. Ferri, G. Liu, and J. Stiglitz, "The procyclical role of rating agencies: evidence from the east Asian crisis," Economic Notes, vol. 28, no. 3, pp. 335-355, 1999.

[14] S. Hoti and M. McAleer, "An empirical assessment of country risk ratings and associated models," Journal of Economic Surveys, vol. 18, no. 4, pp. 539-588, 2004.

[15] M. McAleer, B. da Veiga, and S. Hoti, "Value-at-Risk for country risk ratings," Mathematics and Computers in Simulation, vol. 81, no. 7, pp. 1454-1463, 2011.

[16] Euromoney, 2012, http://www.euromoney.com/poll/10683/ PollsAndAwards/Country-Risk.html.

[17] R. Dornbusch, Y. C. Park, and S. Claessens, "Contagion: understanding how it spreads," World Bank Research Observer, vol. 15, no. 2, pp. 177-197, 2000.

[18] M. Dungey, R. Fry, B. González-Hermosillo, and V. L. Martin, "Empirical modelling of contagion: a review of methodologies," Quantitative Finance, vol. 5, no. 1, pp. 9-24, 2005.

[19] P. Ahluwalia, "Discriminating contagion: an alternative explanation of contagious currency crises," IMF Working Paper $\mathrm{WP} / 00 / 14,2000$.

[20] T. Bayoumi, G. Fazio, M. Kumar, and R. MacDonald, "Fatal attraction: using distance to measure contagion in good times as well as bad," Review of Financial Economics, vol. 16, no. 3, pp. 259-273, 2007.

[21] B. Eichengreen, A. Rose, and C. Wyplosz, "Contagious currency crises," NBER Working Paper W5681, 1996.

[22] J. Sachs, A. Tornell, and A. Velasco, "Financial crises in emerging markets: tssshe lessons from 1995," NBER Working Paper 5576, 1996.

[23] T. Kanungo, D. M. Mount, N. S. Netanyahu, C. D. Piatko, R. Silverman, and A. Y. Wu, "An efficient k-means clustering algorithms: analysis and implementation," IEEE Transactions on Pattern Analysis and Machine Intelligence, vol. 24, no. 7, pp. 881892, 2002.

[24] D. J. C. MacKay, Information Theory, Inference and Learning Algorithms, Cambridge University Press, New York, NY, USA, 2003. 
[25] Human Development Reports, 2011, http://hdr.undp.org/en/ data/profiles/.

[26] R. T. Frambach, "An integrated model of organizational adoption and diffusion of innovations," European Journal of Marketing, vol. 27, no. 5, pp. 22-41, 1993.

[27] V. Mahajan, E. Muller, and F. M. Bass, "New product diffusion models in marketing: a review and directions for research," Journal of Marketing, vol. 54, no. 1, pp. 1-26, 1990.

[28] D. Zhang and A. Ntoko, "Mathematical model of technology diffusion in developing countries," in Computational Methods in Decision-Making, Economics and Finance, vol. 74, pp. 525-539, 2002.

[29] Mathematica, 2012, http://www.wolfram.com/products/ mathematica/.

[30] 2012, http://en.mercopress.com/2010/10/04/uruguay-s-debtgdp-ratio-down-after-five-quarters-running-increases.

[31] Center Intelligence Agency, 2012, https://www.cia.gov/library/ publications/the-world-factbook/rankorder/2004rank.html.

[32] S. Geisser, Predictive Inference, vol. 55, Chapman and Hall, New York, NY, USA, 1993.

[33] R. Kohavi, "A study of cross-validation and bootstrap for accuracy estimation and model selection," in Proceedings of the 14th International Joint Conference on Artificial Intelligence (IJCAI '95), vol. 2, pp. 1137-1143, 1995.

[34] G. H. Golub, M. Heath, and G. Wahba, "Generalized crossvalidation as method for choosing a good ridge parameter," Technometrics, vol. 21, no. 2, pp. 215-223, 1979.

[35] J. Shao, "Linear model selection by cross-validation," Journal of the American Statistical Association, vol. 88, no. 422, pp. 486494, 1993. 


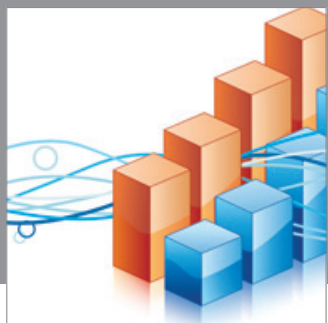

Advances in

Operations Research

mansans

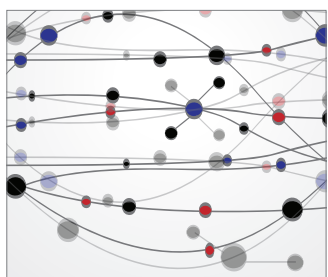

The Scientific World Journal
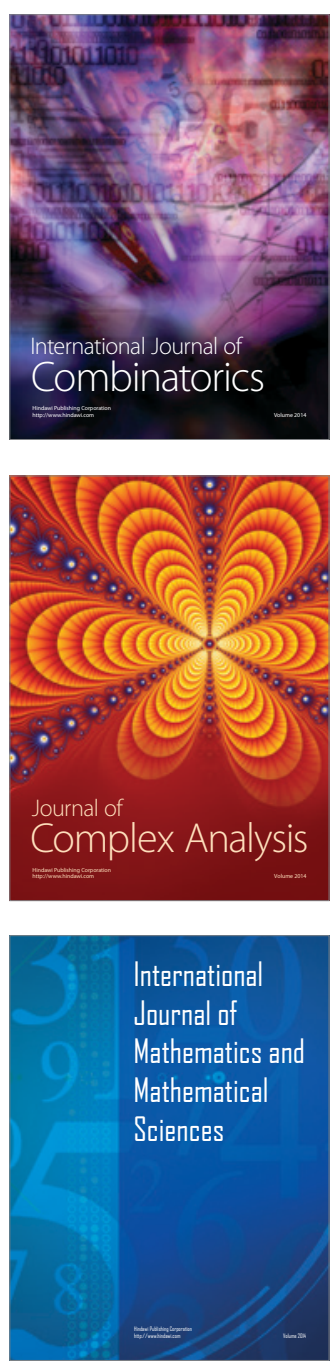
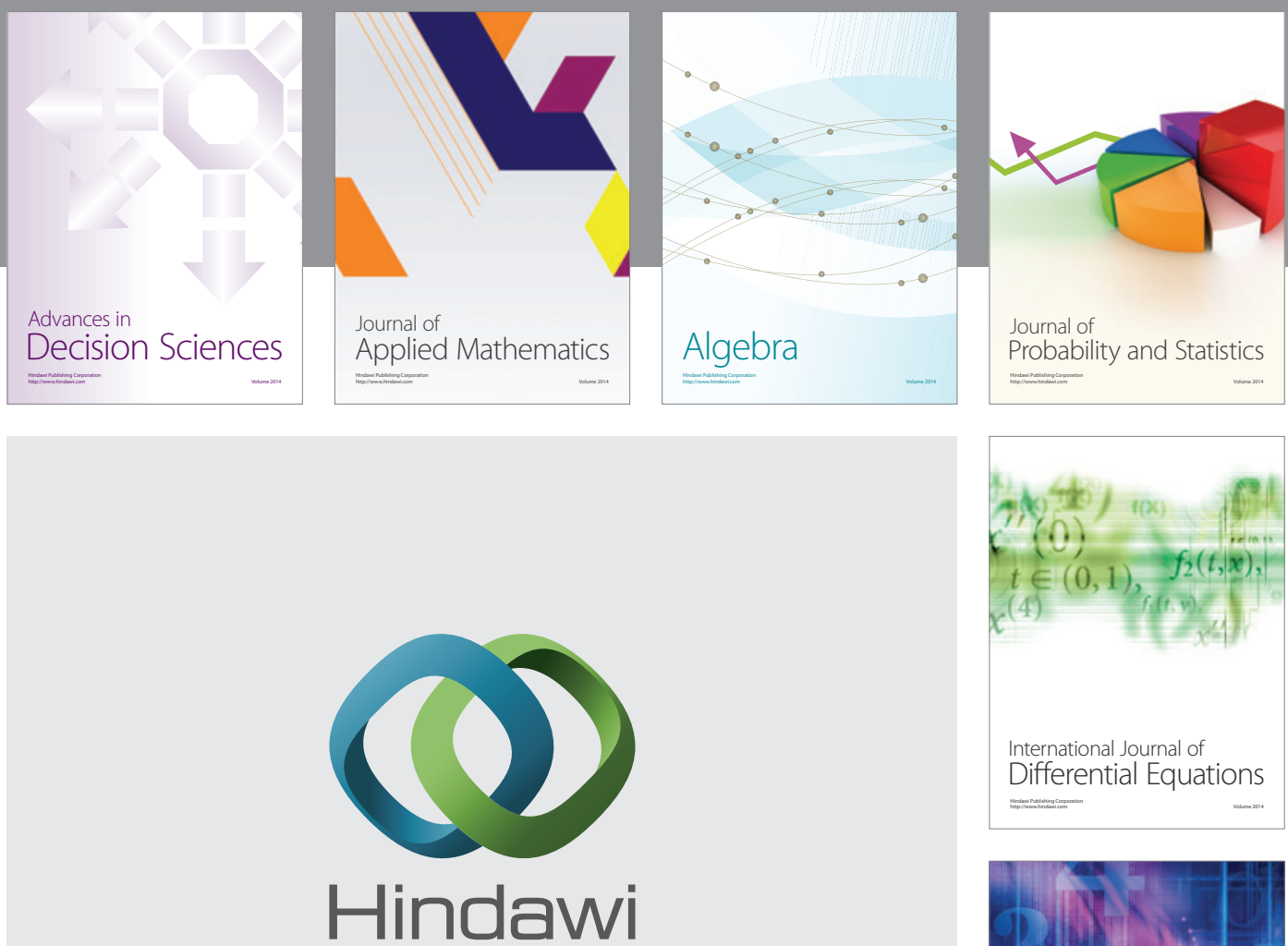

Submit your manuscripts at http://www.hindawi.com
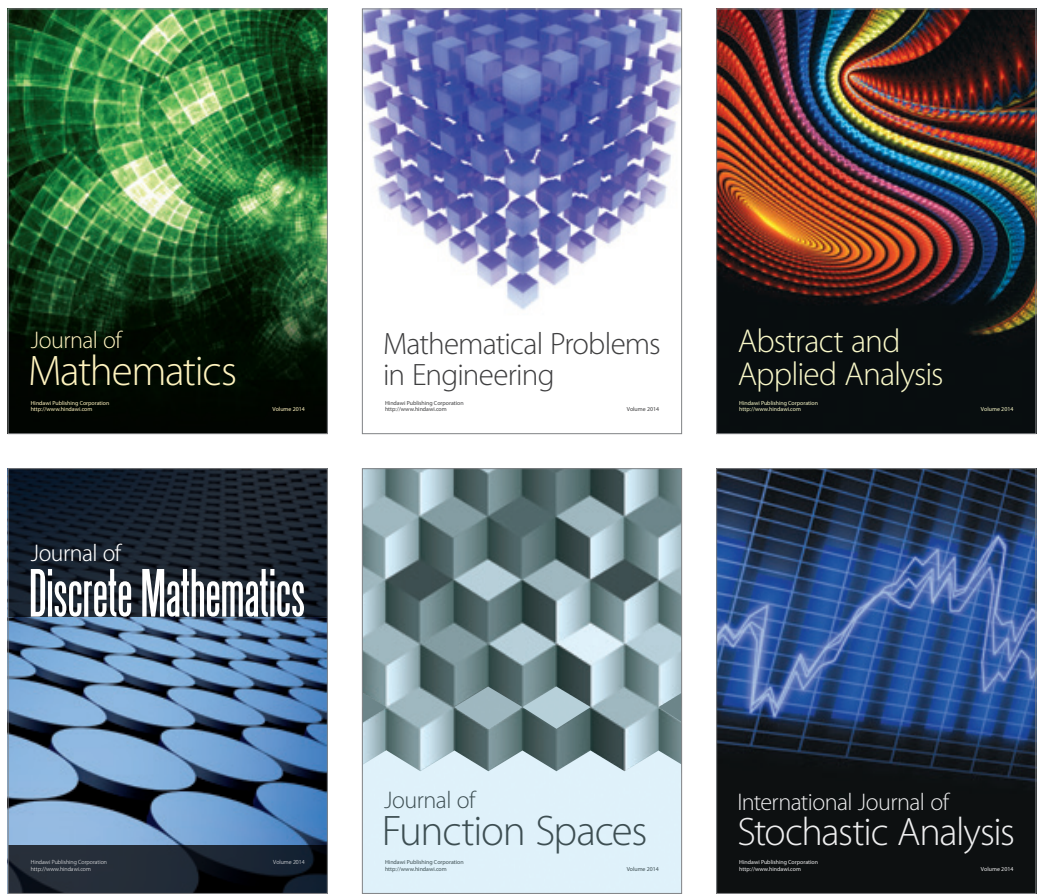

Journal of

Function Spaces

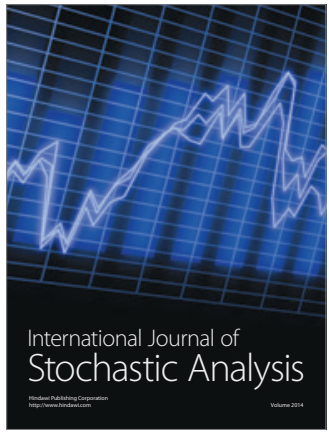

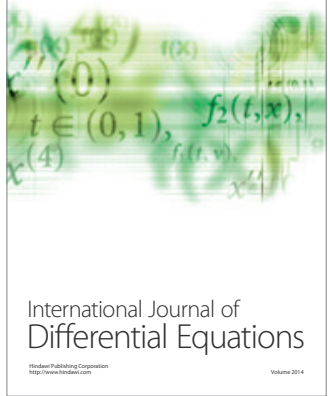
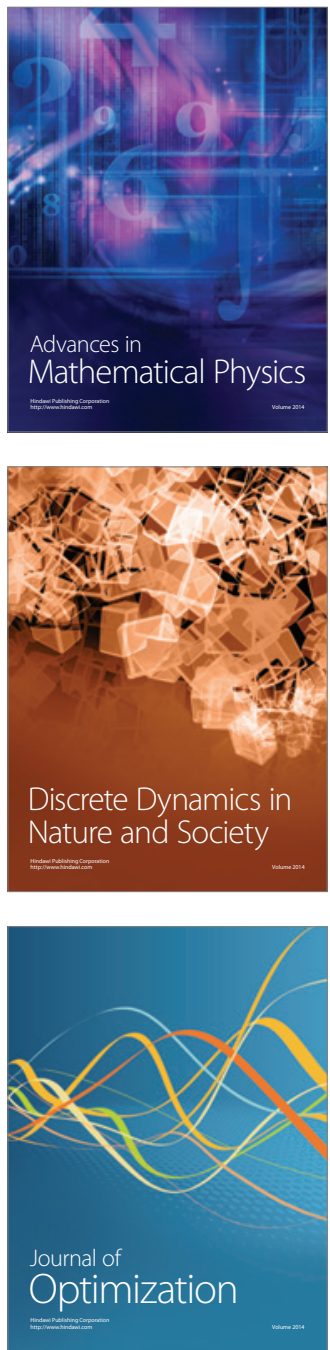